\title{
Behavioral characteristics of the offspring of adolescent rats
}

\footnotetext{
T. Zemunik ${ }^{1}$,

M. Peruzović ${ }^{1}$,

V. Čapkun ${ }^{2}$ and

K. Milković ${ }^{3}$
}

\author{
'Department of Biology, Split University School of Medicine, Split, Croatia \\ ${ }^{2}$ Department of Nuclear Medicine, Split Clinical Hospital, Split, Croatia \\ ${ }^{3}$ Department of Biology, Zagreb University School of Medicine, Zagreb, Croatia
}

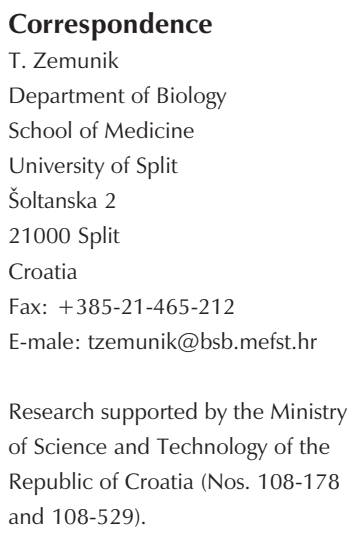

Received February 25, 2002 Accepted November 5, 2002

\begin{abstract}
The aim of this study was to test the hypothesis that, during adulthood, the offspring of adolescent rats differ in emotionality, learning and memory from the offspring of adult rats. The behavior of the offspring of adolescent (age, 50-55 days) and adult rats (age, 90-95 days) was tested in the open field, activity cage, and passive and active avoidance apparatus. The latencies during training and testing in the passive avoidance apparatus of the offspring of adolescent parents were shorter than the latencies of control offspring $(\mathrm{P}<0.001$ on both training and testing days). Offspring of adolescent parents showed shorter latency time in acquisition trials during active avoidance testing compared to control offspring $(\mathrm{P}<0.001)$. They also showed a higher number of active avoidance responses in the last four blocks of acquisition $(\mathrm{P}<0.001)$ and first two blocks of extinction trials $(\mathrm{P}<0.05$ and $\mathrm{P}<0.001$, respectively). The offspring of adolescent parents showed higher latency on the first day of testing in the open field $(\mathrm{P}<0.01)$ and a lower latency on the third day of testing $(\mathrm{P}<0.01)$. They also showed higher activity during all three days of testing (1st and 2nd day: $\mathrm{P}<0.01$; 3rd day: $\mathrm{P}<0.05$ ). The spontaneous activity of the offspring of adolescent parents in the activity cage was higher in the last three intervals of testing $(\mathrm{P}<0.001)$. In summary, the offspring of adolescent parents were less anxious and tended to be more active. The results of two learning and memory tests were opposite, but could be explained by a higher exploratory drive of the offspring of adolescent parents. This was probably due to chronic malnutrition stress and the disturbed mother-infant relationship in the litters of adolescent mothers.
\end{abstract}

\section{Introduction}

The term adolescent pregnancy has been applied to pregnancy at an age and/or developmental stage that is considered premature or inappropriate, especially with respect to its outcome. Young maternal age is believed to be related to, and may be a causative factor of, the higher risk of adverse neonatal outcome (1). Increasing maternal age in humans
Key words

- Adolescence

- Pregnancy

- Behavior

- Learning and memory

- Emotionality (up to the age of 35 years) reduces the risk of a low-birth weight infant. Postnatal mortality rates are approximately twice as high for infants of adolescents under 17 years of age as those for infants of older women (1).

One study suggests that school-age children of adolescents exhibit more behavioral problems and score lower on intellectual tests than school-age children of adults (2). However, it is unclear why these children 
have more developmental problems. Whether the antecedents of these children's behavioral and cognitive problems lie in the motherchild interaction, socioeconomic disadvantage, or in other factors is still unclear (2).

Investigations of the long-lasting effect of adolescent pregnancy on the children require a highly complex multidisciplinary approach. Although there is a large taxonomic difference, laboratory rats can provide a convenient model to study adolescent pregnancies and their consequences. Adequately planned and continuously interpreted experiments using laboratory rats might help to answer some of the questions concerning the adolescent mothers and their offspring in spite of the taxonomic distance between man and rat (3-7).

To our knowledge, at this time only two main research groups are studying the problem using rats, but neither has extended the research beyond two postnatal weeks of the offspring's life (3-7). The beginning of puberty in female rats has been considered to be the day of vaginal opening which is immediately followed by the first ovulation and by sexual receptivity around the 33rd day, when an abrupt increase of testicular weight also occurs in males. Between 41 and 54 days, an irregular estrus cycle appears, while in males additional secondary sex characteristics mature. Normal estrus cycle and adult body weight are established after 54 days of age $(8,9)$. Ninety-day-old animals are considered to be adults and completely full-grown (8).

The aim of the present study was to investigate the association between parental adolescence and its consequences on the emotionality, learning and memory ability of their offspring during adulthood.

\section{Material and Methods}

Animals. Fischer rats were raised under controlled housing conditions (temperature, $22 \pm 1{ }^{\circ} \mathrm{C}$; light schedule, 14-h light/10-h dark). Laboratory food and tap water were available ad libitum. The rats were bred and maintained according to the Guide for Care and Use of Laboratory Animals (NIH, 1996). The Ethics Committee of Split University School of Medicine approved the protocol at the time of grant approval.

\section{Statistical analysis}

Results were analyzed by the SPSS statistical program. The nonparametric MannWhitney test was used to calculate the significance of differences. Group x sex interaction was evaluated by Kruskal-Wallis analysis of variance and by the post hoc MannWhitney test. For repeated measurements, Freedman analysis of variance was used with the Wilcoxon test for post hoc analysis. The results are reported as medians. The acceptable level of significance was set at 0.05 .

\section{Experiment 1}

\section{Methods}

The offspring of adolescent (50-55 days old) rats were compared to the offspring of control (90-95 days old) rats. Four virgin females were housed overnight with one male of the same age per cage. Vaginal smears were examined in the morning over the five subsequent days, and the females with sperm-positive smears were separated for the study. Twelve pregnant females and their respective litters were used in Experiment 1. At weaning (on the 28th day) two males and two females per litter of each group were randomly selected for behavioral testing ( 12 males and 12 females per group for each test). Thereafter the animals were numbered by ear-clipping, caged four per cage according to group and sex, and left undisturbed except for cage cleaning twice a week and behavioral testing. The 81- to 82day-old offspring were tested for passive avoidance, and 83- to 84-day-old offspring 
were tested for active avoidance. Animals were used for only one test. At the beginning of behavioral testing, mean body weight (mean \pm SEM) was: adolescent males $=176$ $\pm 4 \mathrm{~g}$, control $=204 \pm 3 \mathrm{~g}$; adolescent females $=138 \pm 3 \mathrm{~g}$, control $=140 \pm 2 \mathrm{~g}$, respectively.

\section{Behavioral testing}

Passive avoidance apparatus. A twocompartment box divided by a guillotine door was used (Ruder Bošković Institute, Zagreb, Croatia). The smaller, start compartment $(18 \times 10 \times 20 \mathrm{~cm})$ was illuminated by a light at the top of the rear wall. The larger compartment $(30 \times 20 \times 20 \mathrm{~cm})$ was dark and had an electrifiable grid floor connected to a timer. On the first day of testing (training trials) each animal was placed in the small compartment facing the door, which was then raised and the time the animal took to enter the large compartment was recorded. When the animal had all four paws in the large compartment, it received a $0.4-\mathrm{mA} / 2 \mathrm{~s}$ shock and was then removed from the apparatus. The procedure was repeated on the next day (testing trials - retention) but without a shock being given. The latency to enter the large compartment was recorded for each trial. If an animal did not leave the start compartment within $300 \mathrm{~s}$, the trial was terminated and scored as $300 \mathrm{~s}(10)$.

Two-way active avoidance apparatus shuttle box. A plexiglas box $(50 \times 27 \times 25$ $\mathrm{cm}$ ) divided into two equal compartments separated by a $7 \times 8 \mathrm{~cm}$ opening was used (No. 7501, Ugo Basile, Varese, Italy). The conditioned (light and buzzer, $90 \mathrm{~dB}$ ) and unconditioned (0.7-mA shock delivered through the elevated grid floor) stimuli were controlled by an automatic programmer. On the first day of testing (acquisition trials) each animal was allowed 2 min to adapt and then was subjected to 50 avoidance-conditioning trials. During each trial, the conditioned stimulus preceded the shock by $3 \mathrm{~s}$. If the animal crossed to the opposite compart- ment within this period, no shock was received. The intertrial interval was $24 \mathrm{~s}$. On the second day, the animals were submitted to an additional 50 trials but without shock (extinction trials). Each testing session consisted of 50 consecutive trials divided into five blocks of 10 trials each (runs 1-10, 1120, 21-30, 31-40, and 41-50). The total latency time and the number of avoidance responses for each of these blocks were determined on each occasion. The number of fecal boluses deposited during testing was also recorded (10).

\section{Results}

Passive avoidance. Latencies to enter the shock compartment on the first and second days were shorter for offspring from adolescent parents than for offspring from adult rats (group: training $-\mathrm{z}=4.39, \mathrm{P}<0.001$; testing $-\mathrm{Z}=5.02, \mathrm{P}<0.001)$. Control animals on the testing day avoided entering the shock compartment and their latency score was $300 \mathrm{~s}$. Shorter latencies were observed in males on the second day of testing compared to females (sex: testing $-\mathrm{z}=2.24, \mathrm{P}<0.05$, males $=79 \mathrm{~s} v \mathrm{~s}$ females $=300 \mathrm{~s}$ ). In addition, both sexes in the offspring of adolescent rats had shorter latencies compared to control rats during training and on the testing days (group x sex: training $-\chi^{2}=20.9, \mathrm{P}<0.001$; testing $-\chi^{2}=33.9, \mathrm{P}<0.001$; Table 1 ). As shown in Table 1, female offspring of adolescent rats had longer latencies on the second day than males in the same group $(\mathrm{P}<0.001)$.

Repeated measurement using days as the repeated measurement variable showed differences in both groups (adolescent: $\mathrm{z}=3.4$, $\mathrm{P}<0.001$; control: $\mathrm{z}=4.3, \mathrm{P}<0.001)$ and in both sexes (males: $\mathrm{z}=3.4, \mathrm{P}<0.001$; females: $\mathrm{z}=4.3, \mathrm{P}<0.001$ ).

Two-way active avoidance (shuttle box). Offspring of adolescent parents showed shorter latencies in acquisition trials than offspring of adult control rats (adolescent $=$ 
$123 \mathrm{~s} v s$ control $=261.5 \mathrm{~s}, \mathrm{z}=5.4, \mathrm{P}<0.001)$. Kruskal-Wallis analysis of variance showed group $\mathrm{x}$ sex interaction in latencies during acquisition trials $\left(\chi^{2}=32.6, \mathrm{P}<0.001\right)$. Both sexes of offspring of control parents showed longer latencies than male and female offspring of adolescent parents $(\mathrm{P}<0.001$ on both occasions). Within the adolescent group, males also showed longer latency than females $(\mathrm{P}<0.05)$.

Offspring of adolescent parents exhibited a larger number of active avoidance responses in the last four blocks of the acquisition trials (block: 11-20, $\mathrm{z}=3.2 ; 21-30, \mathrm{z}=$

Table 1. Median passive avoidance latencies (s) of the offspring of adolescent and adult control rats at 81 days (training) and 82 days (testing) of life $(N=12$ ).

\begin{tabular}{llccc}
\hline Age (days) & Sex & \multicolumn{2}{c}{ Latency (s) } & P \\
\cline { 3 - 4 } & & $\begin{array}{c}\text { Offspring of } \\
\text { adolescent rats }\end{array}$ & $\begin{array}{c}\text { Offspring of } \\
\text { adult control rats }\end{array}$ & \\
\hline 81 & Male & 7.0 & 28.5 & $<0.01$ \\
(training) & Female & 5.5 & 16.5 & $<0.001$ \\
82 & Male & $6.0^{*}$ & 300.0 & $<0.001$ \\
(testing) & Female & 196.5 & 300.0 & $<0.01$ \\
\hline
\end{tabular}

$\mathrm{P}=$ comparison of offspring from adolescent and adult control rats (Mann-Whitney test). ${ }^{*} P<0.001$, males vs females (Mann-Whitney test).

Figure 1. Median avoidance scores (No.) in the shuttle box during five blocks (10 runs each) of acquisition and extinction trials for the offspring of adolescent (filled columns) and adult control (open columns) 83- and 84-day-old rats $(\mathrm{N}=24)$. The Mann-Whitney test was used to compare offspring from adolescent and adult control animals. $\mathrm{P}<0.01$, blocks of acquisition trials: 11-20, 21-30, 31-40, 41-50; $\mathrm{P}<0.05$, blocks of extinction trials: 1-10, 11-20.

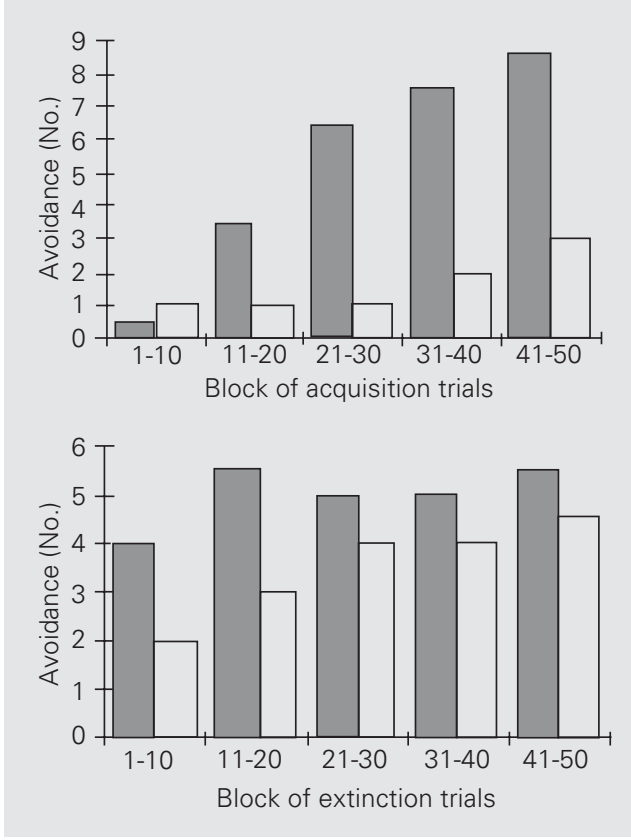

$4.3 ; 31-40, \mathrm{z}=4.4 ; 41-50, \mathrm{z}=5.1, \mathrm{P}<0.001$ for all comparisons; Figure 1) and during the first two blocks of extinction trials (block: 1$10, \mathrm{z}=2.2, \mathrm{P}<0.05 ; 11-20, \mathrm{z}=2.9, \mathrm{P}<0.01$; Figure 1). Group $x$ sex interaction was significant in the last four block of acquisition trials (block: $11-20, \chi^{2}=11.9, \mathrm{P}<0.01 ; 21$ $30, \chi^{2}=20.4, \mathrm{P}<0.001 ; 31-40, \chi^{2}=20.1$, $\left.\mathrm{P}<0.001 ; 41-50, \chi^{2}=27.4, \mathrm{P}<0.001\right)$ as well as in the first two blocks and in the last block of extinction trials (block: $1-10, \chi^{2}=8.3$, $\mathrm{P}<0.05 ; 11-20, \chi^{2}=10.2, \mathrm{P}<0.05 ; 41-50$, $\left.\chi^{2}=9.4, \mathrm{P}<0.05\right)$. Different sex combinations between and within groups contributed to the interaction in acquisition trials (Table 2). Only differences between females of the two groups contributed to interaction of extinction trials $(\mathrm{P}<0.05$ in all comparisons), with females from adolescent parents showing better avoidance scores than females from control parents (block: 1-10 adolescent females $=8 v s$ control females $=2 ; 11-20$ adolescent females $=7.5 v s$ control females $=3 ; 41-50$ adolescent females $=7.5 \mathrm{vs}$ control females $=3.5$ ).

Repeated measurement using the block of trials as the repeated measurement variable showed significant differences in both groups during the acquisition trials (offspring of adolescent parents: $\chi^{2}=64.9, \mathrm{P}<0.001$; offspring of control parents: $\chi^{2}=21.3, \mathrm{P}<0.001$ ).

There was also a difference in the number of defecations, with offspring of adolescent parents defecating more on both testing days (acquisition: adolescent $=5 v s$ control $=$ $1, \mathrm{z}=3.7, \mathrm{P}<0.001$; extinction: adolescent $=$ $2.5 v s$ control $=0, \mathrm{z}=2.4, \mathrm{P}<0.05)$. Group $\mathrm{x}$ sex interaction was also shown in the number of defecations on both testing days (acquisition: $\chi^{2}=13.9, \mathrm{P}<0.01$; extinction: $\chi^{2}=$ $10.6, \mathrm{P}<0.05$ ). During acquisition trials, male and female offspring from adolescent parents showed a higher number of defecations than their counterparts from control parents (males: $\mathrm{P}<0.05$, females: $\mathrm{P}<0.01$ ). During extinction trials, female offspring from adolescent parents showed a higher number of 
defecations than their counterparts from control parents $(\mathrm{P}<0.001)$. Male offspring from control parents defecated more than females of the same group $(\mathrm{P}<0.05)$.

The results of Experiment 1 showed shorter latency time in the passive avoidance apparatus of the offspring of adolescent parents during training and testing days. They also showed shorter latencies in acquisition trials during active avoidance testing and a higher number of active avoidance responses in the last four blocks of acquisition and first two blocks of extinction trials.

\section{Experiment 2}

\section{Methods}

The procedure used to obtain offspring from adolescent and control parents and the number of animals used for testing were the same as described in Experiment 1. The 75- to 77-day-old offspring were subjected to the open-field test and the 78-day-old offspring to the activity cage. At the beginning of behavioral testing, mean body weight was: males from adolescent parents $=171 \pm 3 \mathrm{~g}$, control $=$ $202 \pm 3 \mathrm{~g}$; females from adolescent parents $=$ $141 \pm 2 \mathrm{~g}$, control $=145 \pm 2 \mathrm{~g}$. Different animals were used for each test.

\section{Behavioral testing}

Open field. A white circular field $83 \mathrm{~cm}$ in diameter divided into 18 segments by black lines was used. A 100-W lamp $1.2 \mathrm{~m}$ above the center of the field provided the only light in the testing room. A speaker delivering white noise was turned on during testing to block the effect of eventual external noises. Each animal was placed in the central segment of the field and latency (time the animal remains in the central segment of the field) and activity (number of segments crossed during 3 min of observation) were recorded. The number of fecal boluses deposited during each 3-min session was also recorded. Each animal was tested on 3 con- secutive days at approximately the same time each day, from the 75th to the 77th day of life (10).

The activity cage consists of a plexiglas box $38 \times 20 \times 24 \mathrm{~cm}$ with a grid floor. A very weak electrical current passing through the grids provides a count of ambulatory activity in the cage. Animals were tested on one occasion for $30 \mathrm{~min}$ at 78 days of life (10).

\section{Results}

Open field. On the first day of testing in the open field, offspring from adolescent parents showed a longer latency to start exploratory activity than offspring from adult parents $(\mathrm{z}=2.6, \mathrm{P}<0.01$; Figure 2$)$. On the second day of testing their latency was shorter but the difference from control was not statistically significant, while on the third day of testing latency was significantly less among offspring of adolescent parents compared to control ( $z=3.5, P<0.001$; Figure 2). Females of both groups showed a shorter latency corresponding to that observed for males on the second day of testing (females $=3 \mathrm{~s} v \mathrm{~s}$

\begin{tabular}{|c|c|c|c|c|}
\hline \multirow[t]{2}{*}{ Block of trials } & \multirow[t]{2}{*}{ Sex } & \multicolumn{2}{|c|}{ Avoidance scores (No.) } & \multirow[t]{2}{*}{$P$} \\
\hline & & $\begin{array}{l}\text { Offspring of } \\
\text { adolescent rats }\end{array}$ & $\begin{array}{l}\text { Offspring of } \\
\text { adult control rats }\end{array}$ & \\
\hline \multirow[t]{2}{*}{$1-10$} & Male & 0 & 1.0 & NS \\
\hline & Female & 1.0 & 1.0 & NS \\
\hline \multirow[t]{2}{*}{$11-20$} & Male & 2.5 & 1.0 & NS \\
\hline & Female & 4.0 & 1.0 & $<0.01$ \\
\hline \multirow[t]{2}{*}{$21-30$} & Male & 5.0 & 1.0 & $<0.01$ \\
\hline & Female & 7.5 & 2.0 & $<0.001$ \\
\hline \multirow[t]{2}{*}{$31-40$} & Male & 5.5 & 2.0 & $<0.01$ \\
\hline & Female & 8.5 & 2.5 & $<0.01$ \\
\hline \multirow[t]{2}{*}{$41-50$} & Male & $6.5^{*}$ & 3.0 & $<0.001$ \\
\hline & Female & 10.0 & 2.5 & $<0.001$ \\
\hline
\end{tabular}


males $=12.5 \mathrm{~s}, \mathrm{z}=3.6, \mathrm{P}<0.001)$. KruskalWallis analysis of variance showed group $\mathrm{x}$ sex interaction on all three days of latency analysis (75-day-old offspring: $\chi^{2}=8.7$, $\mathrm{P}<0.05$; 76-day-old offspring: $\chi^{2}=14.7$, $\mathrm{P}<0.01$; 77-day-old offspring: $\chi^{2}=15.6$, $\mathrm{P}<0.001$; Table 3).

Freedman analysis of variance with days as the repeated measurement variable showed

\begin{tabular}{|c|c|c|c|c|}
\hline \multirow[t]{2}{*}{ Age (days) } & \multirow[t]{2}{*}{ Sex } & \multicolumn{2}{|c|}{ Latency (s) } & \multirow[t]{2}{*}{$P$} \\
\hline & & $\begin{array}{l}\text { Offspring of } \\
\text { adolescent rats }\end{array}$ & $\begin{array}{l}\text { Offspring of } \\
\text { adult control rats }\end{array}$ & \\
\hline 75 & $\begin{array}{l}\text { Male } \\
\text { Female }\end{array}$ & $\begin{array}{r}11.1 \\
8.0\end{array}$ & $\begin{array}{l}6.5 \\
4.0\end{array}$ & $\begin{array}{c}\text { NS } \\
<0.05\end{array}$ \\
\hline 76 & $\begin{array}{l}\text { Male } \\
\text { Female }\end{array}$ & $\begin{array}{c}14.5^{*} \\
2.0\end{array}$ & $\begin{array}{l}9.0^{*} \\
5.5\end{array}$ & $\begin{array}{l}\text { NS } \\
\text { NS }\end{array}$ \\
\hline 77 & $\begin{array}{l}\text { Male } \\
\text { Female }\end{array}$ & $\begin{array}{l}1.0 \\
1.0\end{array}$ & $\begin{array}{l}9.5^{*} \\
3.0\end{array}$ & $\begin{array}{l}<0.01 \\
<0.05\end{array}$ \\
\hline
\end{tabular}

$\mathrm{P}=$ comparison of offspring from adolescent and adult control rats (Mann-Whitney test). ${ }^{*} P<0.01$, males vs females (Mann-Whitney test). NS, nonsignificant.

Figure 2. Median open-field latency (s) of the offspring of adolescent (filled columns) and adult control (open columns) rats at the age of 75-77 days $(N=24)$. The Mann-Whitney test was used to compare offspring from adolescent and adult control animals. $P<0.01,75$-day-old offspring; $P<0.001,77$-day-old offspring.

Figure 3. Median open-field activity (No. of floor segments crossed per day) of the offspring of adolescent (filled columns) and adult control (open columns) rats at the age of 75-77 days ( $N$ = 24). The Mann-Whitney test was used to compare offspring from adolescent and adult control animals. $P<0.01,75$-day-old offspring; $P<0.001,76$-day-old offspring; $\quad P<0.05$, 77-day-old offspring.
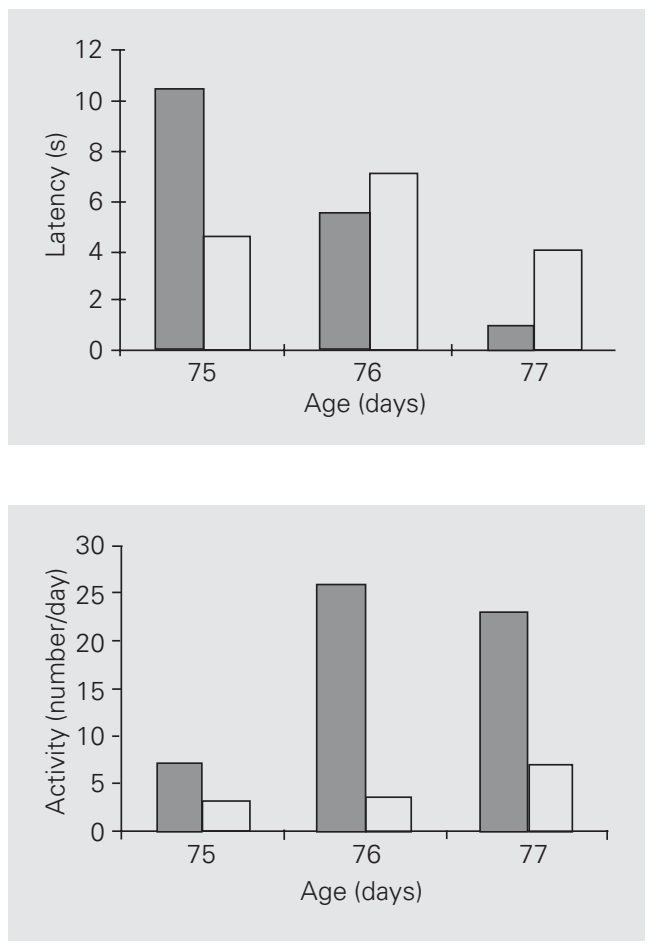

differences in latency in both groups of animals (adolescent: $\chi^{2}=21.4, \mathrm{P}<0.001$; control: $\left.\chi^{2}=6.1, \mathrm{P}<0.05\right)$. Sex differences were also observed in both groups (adolescent: $\chi^{2}=6.5, \mathrm{P}<0.05$; control: $\left.\chi^{2}=6.85, \mathrm{P}<0.05\right)$, as well as group $\mathrm{x}$ sex interaction (adolescent male offspring: $\chi^{2}=13.0, \mathrm{P}<0.001$; adolescent female offspring: $\chi^{2}=11.5, \mathrm{P}<0.01$ ).

Offspring of adolescent parents showed higher activity than offspring of adult control rats on all three days of testing (75-dayold offspring: $\mathrm{z}=2.7, \mathrm{P}<0.01 ; 76$-day-old offspring: $\mathrm{z}=3.3, \mathrm{P}<0.001$; 77-day-old offspring: $\mathrm{z}=2.2, \mathrm{P}<0.05$, Figure 3 ). Males of both groups showed lower activity scores than females on all three days of testing (75day-old offspring: males $=3$ vs females $=$ 5.5, $\mathrm{z}=2.7, \mathrm{P}<0.01$; 76-day-old offspring: males $=3 v$ s females $=26.5, \mathrm{z}=3.7, \mathrm{P}<0.001$; 77-day-old offspring: males $=4 \mathrm{vs}$ females $=$ $23, \mathrm{z}=2.9, \mathrm{P}<0.01)$. Group $\mathrm{x}$ sex interaction was also observed on all three days of testing (75-day-old offspring: $\chi^{2}=15.8, \mathrm{P}<0.001$; 76-day-old offspring: $\chi^{2}=24.7, \mathrm{P}<0.001$; 77-day-old offspring: $\chi^{2}=14.7, \mathrm{P}<0.01$, Table 4).

Repeated measurements using days as the repeated measurement variable showed a difference in activity in the offspring of control parents $\left(\chi^{2}=13.1, \mathrm{P}<0.001\right)$. A sex difference was observed in the offspring of adolescent parents $\left(\chi^{2}=11.1, \mathrm{P}<0.01\right)$. Group $\mathrm{x}$ sex interaction was observed between adolescent male offspring $\left(\chi^{2}=11.6, \mathrm{P}<0.01\right)$ and control female offspring $\left(\chi^{2}=14.4, \mathrm{P}<0.001\right)$.

No significant differences in defecation frequency occurred in the open field. Freedman analysis of variance with days as the repeated measurement variable showed differences in defecation in both animal groups (adolescent: $\chi^{2}=10, \mathrm{P}<0.01$; control: $\chi^{2}=$ 9.3, $\mathrm{P}<0.01)$. A sex difference was observed in the group of offspring of control parents $\left(\chi^{2}=6.5, \mathrm{P}<0.05\right)$. A significant group $\mathrm{x}$ sex interaction was evident between adolescent male offspring $\left(\chi^{2}=11.1, \mathrm{P}<0.01\right)$ and control female offspring $\left(\chi^{2}=8.3, \mathrm{P}<0.05\right)$. 
Activity cage. The spontaneous exploratory activity of offspring from adolescent parents in the activity cage was significantly higher during the last three intervals compared to control (interval: $16-20 \mathrm{~min}, \mathrm{z}=$ 3.69, $\mathrm{P}<0.001 ; 21-25 \mathrm{~min}, \mathrm{z}=4.6, \mathrm{P}<0.001$; 26-30 min, $\mathrm{z}=4.87, \mathrm{P}<0.001$; Figure 4). A significant group $\mathrm{x}$ sex interaction was also evident (interval: $16-20 \mathrm{~min}, \chi^{2}=13.9$, $\mathrm{P}<0.01 ; 21-25 \min , \chi^{2}=21.9, \mathrm{P}<0.001 ; 26-$ $\left.30 \mathrm{~min}, \chi^{2}=25.0, \mathrm{P}<0.001\right)$. Differences between males as well as females of the two groups during all three intervals contributed to this interaction (Table 5).

Freedman analysis of variance with intervals included as the repeated measurement variable showed differences within both groups (offspring of adolescent parents: $\chi^{2}=$ 37.7, $\mathrm{P}<0.001$; offspring of control parents: $\left.\chi^{2}=15.6, \mathrm{P}<0.01\right)$.

No significant sex or group differences in defecation were observed.

The results of Experiment 2 showed higher activity of the offspring of adolescent parents during three days of testing in the open field and higher spontaneous activity in the last three intervals during testing in the activity cage.

\section{Discussion}

Effects of adolescent pregnancies on adult offspring were analyzed in both passive and active avoidance conditioning situations. The offspring of adolescent parents had shorter latencies to enter and re-enter the shock compartment than controls in the passive avoidance box, indicating poorer memory retention. This finding was not supported by the results in the active avoidance shuttle box which showed that the offspring of adolescent parents were more successful in acquisition and extinction trials than the offspring of adult parents, as shown by shorter latency time and increased number of total shock avoidances.

The long-lasting consequences of ado-
Table 4. Median open-field activity (No. of floor segments crossed per day) for the offspring of adolescent and adult control rats at the age of 75-77 days $(N=12)$.

\begin{tabular}{llccr}
\hline Age (days) & Sex & \multicolumn{2}{c}{ Field activity } & P \\
\cline { 3 - 4 } & & $\begin{array}{c}\text { Offspring of } \\
\text { adolescent rats }\end{array}$ & $\begin{array}{c}\text { Offspring of } \\
\text { adult control rats }\end{array}$ & \\
\hline 75 & Male & $4.0^{*}$ & 2.5 & NS \\
76 & Female & 28.5 & 3.0 & $<0.01$ \\
77 & Male & $5.5^{*}$ & $1.0^{*}$ & $<0.05$ \\
& Female & 34.5 & 10.0 & $<0.001$ \\
& Male & 19.0 & 3.0 & $<0.01$ \\
& Female & 24.0 & 21.5 & NS \\
\hline
\end{tabular}

$\mathrm{P}=$ comparison of offspring of adolescent and adult control rats (Mann-Whitney test). ${ }^{*} \mathrm{P}<0.05$, males vs females (Mann-Whitney test). NS, nonsignificant.

Table 5. Median spontaneous activity (counts/15 $\mathrm{min}$ ) for the offspring of adolescent and adult control rats at the age of 78 days $(N=12)$.

\begin{tabular}{llccc}
\hline Time interval (min) & Sex & \multicolumn{2}{c}{ Spontaneous activity } & P \\
\cline { 3 - 4 } & & $\begin{array}{c}\text { Offspring of } \\
\text { adolescent rats }\end{array}$ & $\begin{array}{c}\text { Offspring of } \\
\text { adult control rats }\end{array}$ & \\
\hline \multirow{2}{*}{$0-5$} & Male & 84.0 & 48.0 & NS \\
& Female & 82.5 & 113.5 & NS \\
$6-10$ & Male & 121.0 & 70.0 & NS \\
& Female & 11.5 & 94.0 & NS \\
$11-15$ & Male & 104.0 & 88.0 & NS \\
& Female & 124.0 & 105.5 & NS \\
$16-20$ & Male & 130.0 & 65.0 & $<0.01$ \\
& Female & 126.5 & 61.5 & $<0.05$ \\
$21-25$ & Male & 169.5 & 69.0 & $<0.001$ \\
& Female & 160.0 & 75.0 & $<0.01$ \\
$26-30$ & Male & 164.0 & 56.0 & $<0.001$ \\
& Female & 202.0 & 30.0 & $<0.001$
\end{tabular}

$\mathrm{P}=$ comparison of offspring of adolescent and adult rats (Mann-Whitney test). NS, nonsignificant.

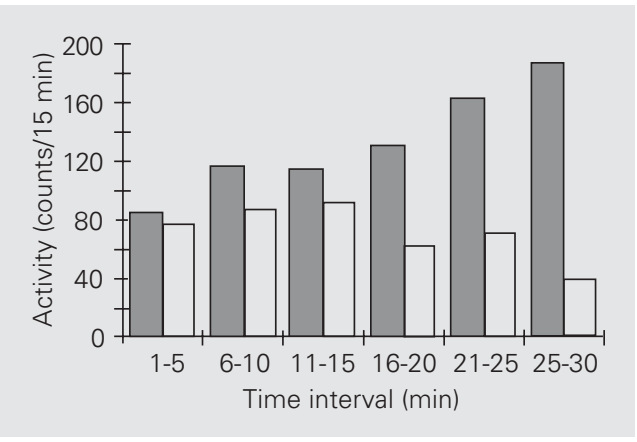

Figure 4. Median spontaneous activity (counts/15 min) in the activity cage of 78-day-old offspring of adolescent (filled columns) and adult control (open columns) rats $(\mathrm{N}=24)$. The Mann-Whitney test was used to compare offspring from adolescent and adult control animals. $P<0.001$, intervals: $16-20,21-25$, 25-30. 
lescent pregnancies on adult offspring were also analyzed in the open-field conditioning situation and in the activity cage. The offspring of adolescent parents after the experience of the first day showed shorter latency to start activity in the open field and higher activity on all three days of testing. They also showed higher spontaneous activity than the offspring of adult parents in the last three intervals in the activity cage. There were no significant differences in defecation scores between groups in either test. The results of these two tests indicated that the offspring of adolescent parents were less emotionally reactive compared to the offspring of adult parents because animals which are less active and defecate more in the open-field situation are considered to be more emotional than animals with high activity and low defecation scores (11).

To our knowledge, a similar observation has not been previously reported. On the basis of our earlier experience, we believe that the behavioral changes observed in the offspring of adolescent parents were the consequences of perinatal stress (12). Chronic stress, which to a degree can explain these results, might be induced in offspring of adolescent parents by insufficient nutrition during perinatal life $(13,14)$. The results of our previous study showed that after an intensive response to birth stress the corticosterone levels of the offspring of adolescent rats decreased below those of the offspring of control rats (15). Two weeks after birth when stabilization of corticosterone levels was expected, the levels were high. This may be due to disturbances of lactation and of the relationship of litter mates (15). It has been reported that chronic stress itself causes disturbances in the circadian rhythm in terms of physiology and endocrinology, and in some types of behavior (16-18). It is possible that adolescent mothers were unable to support the normal growth of their offspring during weaning, as indicated by the reduction of neonate body weight that occurred during postnatal life (12). Hashizume et al. (3) observed a normal body weight gain during the first 15 days of life when the pups of adolescent mothers were fed by an adult control foster mother, whereas feeding by the adolescent mother resulted in a reduced body weight of the control offspring. Male rats were more sensitive than females during chronic perinatal malnutrition and the negative effect was retained until adulthood, a fact also observed in the present study $(12,19)$. Levitsky and Barnes (20) showed that animals submitted to malnutrition in early life such as those who live in a poor environment are more active. Similar results were obtained by Schenck et al. (21), who emphasized that this effect is more pronounced on females, in agreement with the results obtained here for the offspring of adolescent parents.

A disturbed mother-infant relationship in litters of adolescent mothers probably has a negative effect on learning and memory of their offspring but the effect on emotionality is less pronounced (22). Early separation or isolation of pups from the nest during lactation impairs learning and memory functions, whereas a normal relationship between mother and pups in the nest stimulates learning and memory (23). Maternal behavior during the first 10 days of the offspring's life serves to "program" their hypothalamicpituitary-adrenal responses to stress. As adults, the offspring of mothers with a normal relationship with their pups showed reduced plasma adrenocorticotropic hormone and corticosterone responses to acute stress, increased hippocampal glucocorticoid receptor messenger RNA expression, enhanced glucocorticoid feedback sensitivity, and decreased levels of hypothalamic corticotropin-releasing hormone messenger RNA (23). It has also been reported that inhibition of the transport of maternal steroids through the feto-placental barrier can permanently program amygdala glucocorticoid receptor messenger RNA expression and anxiety-like 
behavior in the offspring (24).

The results of both emotionality tests reported here were uniform and showed less expressed emotional reaction to novelty by the offspring of adolescent parents. Both the mild stressful testing in the passive avoidance cage and the more stressful testing in the shuttle box affected the offspring of adolescent parents, but in the opposite direction. The long-term behavioral effect on the offspring of adolescent parents in the shuttle box might be attributed to the alterations in emotionality, non-anxious habituation to a new environment, higher activity and also higher motor capacity. According to our previous study, offspring of adolescent rats showed higher motor activity and physical strength after weaning. The difference persisted among males in adulthood (12). It may be that their higher exploratory drive also caused negative results in passive avoidance. It is important to note that the offspring of adolescent parents showed shorter latency during the training trial, i.e., before any learning in the passive avoidance task.

The fact that various neuropharmacological substances have anxiolytic as well as amnestic effects suggests that neuronal mechanisms of anxiety, learning and memory closely interact $(25,26)$. Ribeiro et al. (25) reported that anxious rats perform better in passive avoidance tasks and worse in active avoidance tasks. In contrast, FernandezTeruel et al. (27) showed that non-anxious rats present a larger number of avoidance scores in the shuttle box. Other investigators believe that differences in anxiety-related behavior do not accompany differences in learning and memory performance (26).

There was no difference in defecation frequency between the two groups in the two emotionality tests, supporting the explanation that offspring of adolescent parents were less emotionally reactive and showed higher expression of exploratory behavior. Offspring of adolescent parents defecated more in the active avoidance response test, a fact that cannot be explained according to this point of view. One reason for this apparent contradiction can be that the anxiety state is not a uniform phenomenon.

In the present study, both male and female offspring were used in order to examine possible sex-related differences. In the open field males are less active and have higher defecation scores than females (11). It seems that the emotionality response of males is influenced by testosterone secretion (13), as also supported by the results of the present study.

In the passive avoidance test, females usually do not retain the memory of the electric shock applied on the first day and quickly enter the dark compartment on the second day of testing (28-30). In the present study, it is possible that the negative experience of the first day caused a strong stress reaction and a slow entrance of adolescent females into the dark compartment of the box on the second day of testing.

Perinatal conditions can contribute to variability in selective responses to stress and novelty in adult rats (17,31). Passive avoidance is a relatively simple behavioral screening task influenced by both cognitive alterations and components of the stress response. Passive avoidance performance is known to be altered by hippocampal lesions because it is well documented that the hippocampus is involved in learning and memory processes $(32,33)$. Altered prenatal conditions (chronic stress and protein malnutrition) can have effects on brain structures, number of receptors and amount of neurotransmitters that consequently may contribute to variability in the animals' behavioral responses $(18,34)$. Rats exposed to high concentrations of glucocorticoids before birth respond to stress in later life by increased glucocorticoid secretion. Perinatal brain exposure to excessive amounts of glucocorticoid leads to premature brain aging. After steroid administration, structural changes can be seen in the large hippocampal pyramidal cells (14).

The offspring of adolescent parents were 
less emotionally reactive and less anxious about novelty. The results of two learning and memory tests were opposite, but they were probably caused by the higher exploratory drive of offspring from adolescent parents. Their higher activity resulted in a better performance in an active avoidance task, but in a worse performance in a passive avoidance task. The relationship between emotionality and learning and memory remains to be clarified. It is possible that the chronic stress of malnutrition and/or disturbed mother-infant relationship in litters from adolescent mothers may affect the behavior of their offspring in adulthood. The current findings also suggest that alterations in perinatal conditions can have cognitive influences on offspring brain structure and function, and consequent selective effects on behavioral responses to novelty in rats.

\section{Acknowledgments}

We thank Mrs. Jolanda Zoković for skillful technical assistance. We are also very grateful to Dr. Marianne K. Steele, NASA Ames Research Center, and Prof. Ana Marušić Zagreb University School of Medicine, for critical comments on the manuscript and language revision.

\section{References}

1. Slap GB \& Schwartz S (1989). Risk factors for low birth weight to adolescent mothers. Journal of Adolescent Health Care, 10: 267274.

2. American Academy of Pediatrics (1989). Adolescent pregnancy. Pediatrics, 83: 132-134.

3. Hashizume K, Ohashi K \& Hamajima F (1991). Adolescent pregnancy and growth of progeny in rats. Physiology and Behavior, 49: 367371.

4. Hashizume K \& Ohashi K (1984). Timing of sexual receptivity and the release of gonadotropins during puberty in female rats. Journal of Reproduction and Fertility, 72: 87-91.

5. Mello MA \& Cury L (1989). Influence of protein-calorie malnutrition on reproductive performance of young and mature rats. Growth, Development, and Aging, 53: 141-144.

6. Mello MA, Cury L, Valle LB \& Oliveira-Filho RM (1987). Proteincalorie malnutrition in the young pregnant rat: factors involved in fetal growth impairment. Brazilian Journal of Medical and Biological Research, 20: 575-577.

7. Mello MA \& Cury L (1988). Maternal adaptations for fetal growth in young malnourished rats. Brazilian Journal of Medical and Biological Research, 21: 1053-1056.

8. Gabriel SM, Roncancio JR \& Ruiz NS (1992). Growth hormone pulsatility and the endocrine milieu during sexual maturation in male and female rats. Neuroendocrinology, 56: 619-628.

9. Trkulja V \& Lacković Z (1996). Involvement of muscarinic receptors in the control of female puberty in the rat. European Journal of Pharmacology, 297: 93-96.

10. Joffe JM, Peruzović M \& Milković K (1990). Progeny of male rats treated with methadone: physiological and behavioural effects. Mutation Research, 229: 210-211.

11. Bureš J, Bureš O \& Huston J (Editors) (1976). Techniques and Basic Experiments for the Study of Brain and Behavior. Elsevier Scientific Publishing Company, Amsterdam, The Netherlands, 54.

12. Zemunik T, Peruzović M, Boban A \& Milković K (1996). Growth and motor activity in the progeny of adolescent rats. Croatian Medical Journal, 37: 210-213.

13. Peruzović M, Joffe JM \& Milković K (1987). Long-term effects of naturally occurring within-litter differences in body weight of rats. Physiology and Behavior, 39: 779-781.

14. Nathanielsz PW (1996). Fetal and neonatal environment has influence on brain development. Lancet, 347: 314.

15. Zemunik T, Peruzović M, Čapkun V, Zekan LJ \& Milković K (2001). Pregnancy in adolescent rats, growth and neurodevelopment. Archives of Physiology and Biochemistry, 109: 450-456.

16. Bauman RA \& Kant GJ (1991). Circadian effects of escapable and inescapable shock on the food intake and wheel running of rats. Physiology and Behavior, 51: 167-174.

17. Boksa P, Wilson D \& Rochford J (1998). Responses to stress and novelty in adult rats born vaginally, by Cesarean section or by Cesarean section with acute anoxia. Biology of the Neonate, 74: 48-59.

18. Restrepo C \& Armario A (1987). Chronic stress alters pituitaryadrenal function in prepubertal male rats. Psychoneuroendocrinology, 12: 393-398.

19. Williams JPG, Tanner JM \& Hughes PCR (1974). Catch-up growth in female rats after growth retardation during the suckling period: comparison with males. Pediatric Research, 8: 157-162.

20. Levitsky DA \& Barnes RH (1972). Nutritional and environmental interactions in the behavioral development of the rat: Long term effects. Science, 176: 68-71.

21. Schenck PE, Slob AK \& van der Werff ten Bosch JJ (1978). Locomotor activity and social behavior of old rats after preweaning undernutrition. Developmental Psychobiology, 11: 205-212.

22. Liu D, Diorio J, Tannenbaum B, Caldji C, Francis D, Freedman A, Sharma S, Pearson D, Plotsky PM \& Meaney MJ (1997). Maternal care, hippocampal glucocorticoid receptors, and hypothalamic-pituitary-adrenal responses to stress. Science, 277: 1659-1662.

23. Smith GJ, Miller JS, Wigal T \& Spear NE (1989). Facilitation of acquisition and retention in preweaning but not postweaning rats by the presence of familiar home-nest material. Behavioral and Neural Biology, 52: 370-385.

24. Welberg LA, Seckl JR \& Holmes MC (2000). Inhibition of 11 betahydroxysteroid dehydrogenase, the foeto-placental barrier to maternal glucocorticoids, permanently programs amygdala GR mRNA expression and anxiety-like behaviour in the offspring. European Jour- 
nal of Neuroscience, 13: 1047-1054.

25. Ribeiro RL, Andreatini R, Wolfman C, Viola H, Medina JH \& Da Cunha C (1999). The "anxiety state" and its relation with rat models of memory and habituation. Neurobiology of Learning and Memory, 72: 78-94.

26. Bert B, Fink H, Huston JP \& Voits M (2002). Fischer 344 and Wistar rats differ in anxiety and habituation but not in water maze performance. Neurobiology of Learning and Memory, 78: 11-22.

27. Fernandez-Teruel A, Escorihuela RM, Nunez JF, Zapata A, Boix F, Salazar W \& Tobena A (1991). The early acquisition of two-way (shuttle box) avoidance as an anxiety-mediated behavior: Psychopharmacological validation. Brain Research Bulletin, 26: 173-176.

28. Fedotova YO (2000). The effects of the hormones of peripheral endocrine glands on the processes of behavior, learning, and memory. Neuroscience and Behavioral Physiology, 30: 75-80.

29. Beatty WW \& Fassler RG (1977). Sex differences in sensitivity to electric shock in rats and hamsters. Bulletin of the Psychonomic Society, 10: 189-190.

30. Hainsbroek RPW, Van Oijen HG \& Van de Poll NE (1984). The pituitary-adrenocortical system is not involved in the sex difference in passive avoidance. Pharmacology, Biochemistry and Behavior, 20: 663-668.

31. Endo $Y \&$ Shiraki K (2000). Behavioral and body temperature in rats following chronic foot shock or psychological stress exposure. Physiology and Behavior, 71: 263-268.

32. Flood JF \& Morley JE (1998). Learning and memory in the SAMP8 mouse. Neuroscience and Biobehavioral Reviews, 22: 1-20.

33. Devinsky O, Morrell MJ \& Vogt BA (1995). Contributions of anterior cingulate cortex to behaviour. Brain, 118: 279-306.

34. Galler JR, Tonkiss J \& Maldonando-Irizarry CS (1994). Prenatal protein malnutrition and home orientation in the rat. Physiology and Behavior, 55: 993-996. 